\title{
LITERATURAS BRASILEIRA E CABO-VERDIANA PARA A APRENDIZAGEM AFRO-BRASILEIRA
}

\author{
BRAZILIAN AND CAPE VERDIAN \\ LITERATURES FOR AFRO-BRAZILIAN \\ LEARNING
}

Norma Sueli Rosa Lima ${ }^{1}$

\section{RESUMO}

Este artigo se propõe a examinar o diálogo entre as produções literárias do Brasil e de Cabo Verde sob o ponto de vista do protagonismo e da representatividade da oralidade (crioulo/português brasileiro), nas perspectivas colonial e pós-colonial e de suas especificidades culturais e étnicas.

PALAVRAS-CHAVE: Literaturas de língua portuguesa; oralidade; crioulo.

\section{ABSTRACT}

This article proposes to examine the dialogue between the literary productions from Brazil and Cape Verde from the point of view of the role and representation of orality (Creole / Brazilian Portuguese), colonial and post-colonial perspectives and their cultural and ethnic specificities.

KEYWORDS: Literatures of Portuguese; orality; creole. 


\section{LÍNGUAS QUE SE ENTRELAÇAM}

As leis $\mathrm{n}^{\circ} 10.639 / 2003$ e $\mathrm{n}^{\circ} 11.645 / 2007$, que promovem o ensino da cultura afro-brasileira e indígena e complementam a Lei de Diretrizes e Bases da Educação Nacional ( ${ }^{\circ}$ 9.394/1996), obtiveram avanços inegáveis nos últimos tempos. Ainda que em treze anos não se tenha alcançado todos os objetivos, houve empenhos individuais ou coletivos notáveis, com inúmeros debates e publicações institucionais, bem como pesquisas acadêmicas no âmbito da graduação e da pós-graduação, entre outras ações.

As reflexões deste artigo têm como perspectiva a aproximação entre o crioulo de Cabo Verde e o nosso português brasileiro, que buscaram (e ainda estão nessa procura) se constituir como instâncias de interação nos textos literários. Assim, o fenômeno da crioulização da língua, evidenciado nos textos das literaturas brasileira (ou afro-brasileira, se compreendida a partir dos temas abordados e voltados para a temática africana, ainda que não tenha sido produzida por autores afrodescendentes) e cabo-verdiana, constitui a nosso ver um ganho cultural, pela presença das vozes que, se abafadas em outras instâncias sociais, nestes espaços utópicos se fazem presentes.

O ciclo do mar forjou, pois, a nossa insularidade, mas também levou-nos a descobrir que se o mundo começa em nossa casa, o universo não se restringe apenas às nossas ilhas. Daí a nossa grande vocação ao diálogo e à cooperação, numa perspectiva de reconversão constante, de reconstrução inacabável e de afirmação assumida de uma crioulidade com personalidade recriada diante do outro e com quem dialoga, com quem coopera. (VEIGA,1998, p. 9-10)

A constante busca por um outro lugar que problematize o sentido vertical das relações autoritárias e hegemônicas é inerente à arte, pois a condição utópica está na essência da criação artística (COELHO NETO, 1987). Se a motivação do sonho é uma característica inerente ao humano - "Alterando um conceito de Otto Ranke sobre o mito, podemos dizer que literatura é o sonho acordado das civilizações" (CANDIDO, 2004, p. 175) -, nas literaturas brasileira e cabo-verdiana os lugares destinados à demarcação dos espaços orais dos segmentos não escolarizados e/ou representantes das expressivas línguas nativas ou nacionais sempre estiveram garantidos em obras compromissadas com a quebra de paradigmas. Estas manifestações, vertidas para a escrita, não previam a perspectiva de seu rebaixamento diante de formas hierarquizadas.

No Brasil Colonial, expressar-se em português era ter a legitimação de "civilização"; por isso, os diferentes falares (dos indígenas e dos africanos escravizados) foram, sistematicamente, perseguidos e considerados "inferiores" (o tupi-guarani, a língua geral ou o nheengatu, extinto após a expulsão dos jesuítas pelo Marquês de Pombal, deram à língua portuguesa, inicialmente, estatuto de língua nacional), embora o acesso à escola fosse privilégio, e a educação primária, obrigatória apenas no Brasil republicano 
da década de 1930. Em Cabo Verde, com a língua portuguesa (considerada oficial) coexistiu o crioulo até a época da Independência do Arquipélago (1975), embora veiculado apenas em espaços não institucionais e proibido na escola; havia, portanto, espaço para o bilinguismo. Se no Brasil isto foi vetado, talvez se possa afirmar ter existido na manifestação oral do que se convencionou chamar de "português brasileiro".

$\mathrm{Na}$ verdade, desde o século XIX houve debates acerca da outra expressão modulada da Língua Portuguesa Oficial, como ocorreu no período do Segundo Reinado; porém, as gramáticas publicadas naquela fase elegeram, como parâmetro, a língua de Portugal, tendo sido esta orientação seguida por aquelas que a sucederam. Ao ser essa língua privilegiada como expressão legítima, todo o traço oriundo de suas variantes foi considerado "erro", deixando de serem analisadas as contribuições orais do português africanizado, falado majoritariamente pela população brasileira. Algumas só foram consideradas para compor textos da fase do Romantismo indianista, quando os autores se voltaram para citações lexicais retiradas daquela antiga língua geral, outrora banida, agora eleita como "representação da nossa identidade nacional" - em simbologia de um indígena homenageado apenas na literatura, já que ele se mantinha marginalizado e compreendido como bárbaro.

\section{OS 80 ANOS DE CLARIDADE: REVISTA DE ARTE E DE LETRAS}

Em março de 1936, enfrentando contexto tremendamente adverso e seguindo a tradição de uma imprensa desafiadora, foi lançado o primeiro número da revista Claridade, o qual seria seguido por outros oito exemplares, bastante espaçados em seus trinta anos de existência, que foi até dezembro de 1966. Como é comum em toda vanguarda, não foram poucas as polêmicas e as críticas que seus fundadores sofreram, como também são ainda constantes as remissões (no sentido amplo do termo) às obras de Baltasar Lopes, Jorge Barbosa e Manuel Lopes; e, embora não se conteste a qualidade poética da obra de Barbosa, a importância da pesquisa de Baltasar e a força da prosa de Lopes, sempre foram mais uníssonos os gritos contra o "pontífice do evasionismo", os alertas da ausência de mulheres colaboradoras em suas edições, as certezas de seu conteúdo claridoso colaboracionista com os, então, colonizadores.

Estas e outras postulações acerca da produção claridosa se inserem na ambiência da própria nação crioula cabo-verdiana, na perspectiva de ela ter sido avaliada, enquanto cultura híbrida, em contraponto com o continente africano, como resultado de uma política assimilacionista implementada pela civilização lusa ocidental. Deste modo, os cabo-verdianos foram encarados através do mito da mestiçagem que promovia "uma perda em termos da especificidade da cultura negra" (HERNANDEZ, 2002, p. 99), e o arquipélago, espalhado no Oceano Atlântico - e, portanto, fora do continente africano -, serviu de combustível para a construção de um 
imaginário luso que se valia de Cabo Verde para alimentar a falsa ideia de irmandade entre Portugal e suas colônias, não designadas como tais, e sim na eufemística expressão "extensões do Ultramar".

Não tendo sido incluído no Código do Indigenato e situado em uma condição de cidadania portuguesa desde 1914, na realidade o cabo-verdiano foi vítima da utilização de sua composição mestiça de formação (com o povoamento das ilhas desabitadas e descobertas no século XV) como auxílio às perversas teorias de aculturação, quando essa mistura parecia evidenciar um consequente embranquecimento, estando ainda muito distante das percepções mais recentes que preveem outra construção para as identidades, a partir de uma posição basicamente simpática à afirmação de que elas, modernamente, estariam sendo "descentradas", isto é, deslocadas ou fragmentadas (HALL, 2000, p. 8).

O fato de Cabo Verde ter sido escolhido pelo discurso colonialista para exemplificar a falsa teoria harmônica entre raças colaborou negativamente para a má recepção e julgamento preconceituoso do conteúdo de Claridade, até porque provavelmente pouquíssimos dos seus maiores críticos tenham lido atentamente os seus exemplares escassos que circulavam mais em Portugal (publicadas e censuradas por lá) do que nas ilhas. Felizmente, em comemoração aos seus 80 anos, uma outra edição será publicada pela Media Comunicações - pelo menos foi o que garantiu, há pouco tempo, o Ministro da Cultura do Arquipélago Abraão Vicente. A edição mais recente, fac-similada, que li integralmente para a confecção da minha tese de doutorado (LIMA, 2000), foi publicada há 30 anos e organizada por Manuel Ferreira (1986), com tiragem de 1.300 exemplares.

No atual contexto das teorias pós-coloniais, urge rever postulações a respeito da revista e de seus principais autores, e creio que o octogésimo aniversário seja excelente oportunidade para esta breve homenagem que aqui lhe faço, aliás, não de hoje. Atualmente, um tipo diferente de mudança estrutural está transformando as sociedades modernas ao fragmentar paisagens culturais de classe, gênero, sexualidade, etnia, raça e nacionalidade, diferentemente das sólidas (e fechadas) construções identitárias do passado; mas, na essência cabo-verdiana, estiveram sempre presentes as formulações modernas de Stuart Hall sobre as "concepções mutantes do sujeito humano" e seus descentramentos. Porém, elas eram apreendidas não como diversidade e riqueza, e sim como aculturação e perda, porque percebidas em polos de atrito afrocêntricos e eurocêntricos.

Em linhas gerais podemos dizer que o posicionamento eurocêntrico nasce de uma desadequação dos parâmetros do discurso crítico relativamente à literatura e cultura africanas, uma vez que o ponto de partida é o cânone ocidental, e a utensilagem teórico-crítica tem respaldo em correntes como o new criticism, o estruturalismo, e outras.

O segundo posicionamento, afrocentrista, por seu turno, com forte enraizamento nativista e local, reivindica, entre vários aspectos, a legitimidade do conhecimento da cultura africana, a necessidade de uma teorização 
enquadrada na cultura africana, bem como pode tomar posições liminarmente xenófobas, reclamando a origem, ou o ser africano, para a compreensão e análise crítica destas literaturas. (LEITE, 2016, p. 143)

Recentemente, os próprios autores africanos têm chamado a atenção tanto para o caráter plural da África quanto para a sua abertura ao diálogo com as próprias tradições e com outras, de outros continentes, sem serem estas relações compreendidas sob a égide da ocidentalização ou da aculturação (HOUNTONDJI, 2010, p. 269). Pensar as diferenças entre as culturas africanas implica não operar acriticamente a transferência de teorias explicativas de uma situação histórica para espaços outros apenas pela sua proximidade afectiva ou conveniência ideológica, ensina MATA (2003, p. 36), e é neste sentido que me debruço a examinar os contatos culturais e de linguagens estabelecidos entre Brasil e Cabo Verde.

\section{DAS LÍNGUAS LITERÁRIAS: A BRASILEIRA E A CABOVERDIANA}

A investigação real pelo uso de uma fala brasileira, na nossa literatura, somente ocorrerá com o Modernismo brasileiro, que, já no "Manifesto da Poesia Pau Brasil" de 1924, trouxe uma série de reivindicações de um novo olhar para a cultura brasileira. Oswald de Andrade denunciou o abandono das expressões legítimas do falar brasileiro, postulando para ele um lugar:

A língua sem arcaísmos, sem erudição. Natural e neológica. A contribuição milionária de todos os erros. Como falamos. Como somos. (ANDRADE, 1985, p. 293)

Nunca será demais sublinhar que os modernistas brasileiros compartilhavam, em 1922, das reflexões do Centenário de Independência do Brasil, "A nossa independência ainda não foi proclamada". (ANDRADE, 1985 , p. 345). A busca pela expressão da brasilidade esbarrava no "lado doutor", "no lado citação" da sociedade brasileira, ainda incrivelmente sintonizada com a oratória de verniz das primeiras academias (CANDIDO, 2002), por isso o narrador de Macunaíma, obra também modernista de Mário de Andrade, reforçou a importância da oralidade na medida em que a estória sobre o herói sem nenhum caráter só pôde ser contada aos leitores por ter sido ouvida de um papagaio, o único sobrevivente da tribo. A possibilidade da existência da narrativa, que agora lemos, somente porque uma ave a pôde contar, ironizou o cânone escrito e reposicionou o lugar valoroso da oralidade em nossa literatura, quando a questão da língua portuguesa/língua nacional contextualizou-se na proposta antropofágica, exibindo-se de xenofobismo. (SANTILLI, 2003, p. 40).

Não havia mais ninguém lá. Dera tangolomângolo na tribo Tapanhumas e os filhos dela se acabaram de um a um. Não havia mais ninguém lá. Aqueles lugares aqueles campos furos puxadouros arrastadouros meios-barrancos, aqueles 
matos misteriosos, tudo era solidão do deserto... Um silêncio imenso dormia à beira-rio do Uraricoera.

Nenhum conhecido sobre a terra não sabia nem falar da tribo nem contar aqueles casos tão pançudos. Quem que podia saber do herói? [...]

Então o homem descobriu na ramaria um papagaio verde de bico dourado espiando pra ele. [...] Então o pássaro principiou falando numa fala mansa, muito nova, muito! que era canto e que era caxiri com mel-de-pau, [...]

A tribo se acabara, a família virara sombras, a maloca ruíra minada pelas saúvas e Macunaíma subira para o céu, porém ficara o aruaí do séquito daqueles tempos de dantes em que o herói fora o grande Macunaíma imperador. E só o papagaio no silêncio do Uraricoera preservava do esquecimento os casos e a fala desaparecida. Só o papagaio conservava no silêncio as frases e feitos do herói.

Tudo ele contou pro homem e depois abriu asa rumo de Lisboa. E o homem sou eu, minha gente, e eu fiquei pra vos contar a história. Por isso que vim aqui. Me acocorei em riba destas folhas, catei meus carrapatos, ponteei na violinha e em toque rasgado botei a boca no mundo cantando na fala impura as frases e os casos de Macunaíma, herói de nossa gente.

Tem mais não. (ANDRADE, 1991, p. 185-186)

Os modernistas, com os quais tantos autores cabo-verdianos dialogaram (e ainda dialogam), denunciaram o lugar marginal ocupado pela oralidade naquela sociedade brasileira do início do século XX. Nesta rapsódia ocorreu um tipo de inserção do tupi (língua exterminada, como Macunaíma) diferenciado do que acontecia nos textos indianistas do século XIX, pois ainda que o aruaí ("ave" em tupi-guarani) tivesse contado a estória e se retirado para Lisboa, o narrador não estava esperançoso de que a saga de Macunaíma fosse perpetuada por outros cantadores: “Tem mais não", finalizara, demarcando o não espaço para a oralidade, ao mesmo tempo em que denunciava a destruição das comunidades ameríndias por uma "civilização" feroz. Este exemplo, entre muitos que poderíamos citar ou lembrar, a literatura está atenta em desvelar.

Quase cem anos depois das publicações do "Manifesto Pau-Brasil” e de Macunaíma, já existem ações sistematizadas em prol da atenção ao aspecto polifônico de nossas falas, e a língua portuguesa, segundo a Constituição de 1988, é o idioma oficial; ela possui um caráter plural e não mais o nacional expressivo de uma nação imaginária construído pelas forças hegemônicas (ANDERSON, 1989), ainda que não tenhamos o bilinguismo no sentido oficial, pois as línguas indígenas existentes (cerca de 250, segundo a Unesco), mesmo que reconhecidas, não circulam por nosso sistema linguístico, estando presentes no léxico de nosso idioma e nas comunidades que ainda tentam mantê-las vivas. O mesmo ocorre com as expressões afri- 
canas resistentes nas comunidades quilombolas (espaços de terras tituladas pelo governo federal e disputadas pelos grandes proprietários e grileiros) e nos espaços das religiões afro-brasileiras. Em algumas dessas manifestações afro-brasileiras ocorre a mistura do quimbundo com a língua portuguesa, através do aportuguesamento principalmente nas estruturas da sintática e da semântica. Deste modo, temos, por exemplo: "Vimbundo está cupopiando no injó do tata", significando "O homem preto está falando na casa do pai”. Nas últimas décadas, houve a implementação de esforços a fim de formar professores direcionados à atuação nos campos das comunidades indígena e quilombola, para a manutenção de suas tradições, com material adequado, diferenciado da educação formal brasileira e elaborado com a colaboração dessas comunidades (FRY, VOGT, 1996, p. 86).

Apesar de tudo, pouco se sabe a respeito das línguas africanas faladas no Brasil, pois os documentos linguísticos do tempo da escravidão e os papéis oficiais relativos ao tráfico, que poderiam ser um valoroso auxílio, foram destruídos por ordem governamental em 1891 com o objetivo não confessado de evitar o pagamento de indenizações aos senhores de escravos. Essa dificuldade, porém, tem sido vencida por pesquisadores esforçados em mapear o importante repertório de mais de 5 milhões de africanos para cá transplantados; por isso, temos sido presenteados por publicações que ajudam a compreender a importância de trabalhos voltados para a reivindicação da fala dos ex-cêntricos, no sentido do resgate de contribuições marginalizadas porque interpretadas não do ponto de vista da construção, mas sim do atraso ou da negação de sua importância.

Do mesmo modo, o incansável trabalho de escritores cabo-verdianos, como Baltasar Lopes e Manuel Veiga (mais recentemente), para a legitimação do crioulo como riqueza da oralidade cabo-verdiana e expressão identitária vem revelando que a "atitude dos intelectuais cabo-verdianos, de oposição aos padrões hegemônicos provenientes da metrópole, era correlata à obsessão de procura de origens - étnicas e culturais - que sensibilizava a intelectualidade africana do continente." (ABDALA JÚNIOR, 2003 , p. 263) A proposta de um alfabeto unificado para a escrita cabo-verdiana - Lupeki - é recente (1998) e pretende incluir todas as variantes das ilhas, sendo implementado pela via do ensino, através da formação de professores preparados para lecionarem o crioulo nas salas de aula. Embora a sua tentativa de oficialização não seja consenso e venha gerando debates no arquipélago, o fato de fazer parte do currículo das escolas islenhas é de suma importância, pois no contexto colonial essa fala era condenada, sendo culpabilizada pela não aprendizagem da língua portuguesa:

A criança cabo-verdiana é confrontada, ao iniciar a sua escolarização, com uma língua de ensino (língua portuguesa) diferente de sua língua materna (crioulo), que é necessário dominar o mais breve possível pois o sucesso da sua e s c o larização depende das suas aquisições linguísticas em língua portuguesa. [...] 
A aprendizagem da língua segunda consiste numa reeducação: é preciso construir um conjunto de novos hábitos verbais e suprimir interferências entre este conjunto e o dos hábitos adquiridos em língua materna. (GOMES, 1996, p. 9 e p. 20)

Estas duas transcrições retiradas do livro Projeto multidimensional para a aprendizagem da Lingua Portuguesa em Cabo Verde indicam uma hierarquia entre as línguas (a nativa e a aprendida na escola), reproduzindo o conceito de oralidade como a presença de interferência perniciosa impeditiva do sucesso do indivíduo, posto que ele estaria impedido de dominar, plenamente, a língua oficial, a qual possibilitaria a inserção em um mundo de possibilidades superiores; por isso, não apenas a convivência respeitosa de ambas, no ambiente do bilinguismo (que, como observou Manuel Veiga, "não é apenas crioulo/português, mas crioulo/inglês ou crioulo/francês"), é necessária, como também o é a sua inserção no espaço institucional da escola.

Possuindo características de uso, interação e caráter social, como definiu Bakhtin (2011), a língua assume perspectiva de linguagem ao incorporar suas marcas culturais e, nos casos do crioulo e do português brasileiro, constituir tecidos de vozes em pluralidade indicativa do próprio caráter híbrido das culturas mestiças de Cabo Verde e do Brasil, sem isto significar apagamento das marcas africanas (no arquipélago e aqui) ou das indígenas (no caso brasileiro). Por outro lado, é compreensível que, no caso da investigação das amplas variedades deste crioulo, as utilizadas em São Tiago (onde se localiza a capital e a ilha de maior população) e São Vicente (a segunda ilha mais populosa) sejam priorizadas (VEIGA, 2000, p. 8). A complexidade da eleição de uma entre as variedades linguísticas foi evidenciada desde a fase das lutas de Cabo Verde por sua libertação da condição de colônia.

Claro que nas nossas escolas temos que tirar tudo quanto era feito pelos colonialistas, que mostram a mentalidade dos colonialistas. [...] Devemos evitar o complexo de superioridade da parte daqueles que sabem alguma coisa e o complexo de inferioridade da parte daqueles que não sabem. Porque uma pessoa que é capaz de ensinar não deve afastar-se de ninguém, quanto mais agora do nosso povo. Pelo contrário, deve mergulhar no nosso povo cada vez mais. [...] há camaradas que pensam que, para ensinar na nossa terra, é fundamental ensinar em crioulo já. Então outros pensam que é melhor ensinar em fula, mandinga, em balanta. Isso é muito agradável de ouvir; os balantas se ouvirem isso ficam muito contentes, mas agora não é possível. Como é que vamos escrever balanta, agora? Quem é que sabe a fonética do balanta? Ainda não se sabe. É preciso estudar primeiro, mesmo o crioulo. Eu escrevo, por exemplo, $n^{\prime} c a$ na bai* (nota do editor: não vou!). Um outro pode escrever, por exemplo, $n^{\prime} k a$ na bai. Dá na mesma. Não se pode ensinar assim. Para ensinar 
uma língua escrita é preciso ter uma maneira certa de a escrever, para que todos a escrevam da mesma maneira, senão é uma confusão do diabo. (CABRAL, 1974, p. 211-213)

No calor da luta armada por Cabo Verde e Guiné-Bissau, essas reflexões do líder guerrilheiro e humanista Amílcar evidenciaram o crioulo como símbolo de contestação e resistência, no contexto colonial e ditatorial.

$\mathrm{O}$ estatuto do $\mathrm{CvV}^{2}$, no período colonial, evoluiu de "composto monstruoso", "gíria ridícula" e "miscelânea sem regras nem gramática" para o de dialecto. Aos olhos de vários cultores da língua portuguesa, o ccv era considerado como "atentório à unidade do império português" e, por isso, devia ser proibido ou, mesmo, banido. (VEIGA, 2006, p. 27)

Considera-se que a partir dos anos 60 o crioulo assumiu expressão estética e combativa na presença de autores como B. Leza, Sérgio Fruzoni, Kaoberidano Dambará, entre outros. No contexto da Pós-Independência houve a experiência, até então inédita, da edição do primeiro romance em escrita crioula, Odju d’agu, de Manuel Veiga, lançado em 1987 e reescrito em 2009. Há, ainda, de se fazer menção às pesquisas nas áreas de graduação e de pós-graduação da Universidade de Cabo Verde que abordam o tema e têm sido cada vez mais numerosas; entretanto, apesar de todo o indiscutível avanço, deve-se chamar a atenção para que esta riqueza oral não seja considerada na perspectiva da diglosia (VEIGA, 2006, p. 30-34).

\section{CONSIDERAÇÕES FINAIS}

$\mathrm{Na}$ perspectiva contemporânea, os exames do ensino e da legislação do crioulo não mais são desenvolvidos do ponto de vista da manifestação reativa de um estatuto da cor local contra uma situação de anulação das marcas identitárias (como ocorria no período colonial), mas sim como expressão dialógica originada naturalmente do contato com outras culturas. Considerar essa base heterogênea sem legar à parte africana um status desprestigiado é o que ainda parece se apresentar como desafio.

Na mesma perspectiva, no Brasil o ensino da Linguística (a partir de meados do século XX) auxiliou a repensar a sarjeta na qual fora jogado o português brasileiro, derivando daí outras práticas como as publicações de gramáticas desta variante, as quais evidenciam o fato de a norma culta ser apenas uma entre as várias linguagens existentes. As novas fronteiras não devem ser de separação, mas de contato, como diversos autores das literaturas brasileira e caboverdiana já vinham assinalando em seus textos poéticos e em prosa, sem a desfaçatez dos conflitos que esses contatos geram no pensamento de uma falsa mestiçagem harmoniosa, pois "não se trata efetivamente do mundo que o português criou, mas de um mundo que foi construído comunitariamente por todos nós e quase sempre contra o poder coercitivo do Estado, pois que, em termos culturais, o mundo se criouliza, torna-se mais mestiço, mesclado, abrindo-se cada vez mais para a 
consideração das formulações híbridas" (ABDALA JÚNIOR, 2004, p. 15). A perspectiva da expressão das linguagens na rede de intertextualidades e afinidades com outras literaturas de língua portuguesa, antes de representar perdas identitárias, assume caráter de ganho. Posicionar outras linguagens paritariamente ao português oficial é evidenciar o que as literaturas brasileira e cabo-verdiana já realizam há tempos: utopia de línguas que se roçam, o português brasileiro e o crioulo.

\section{REFERÊNCIAS BIBLIOGRÁFICAS}

ABDALA JÚNIOR, Benjamin (Org.). Margens da cultura: mestiçagem, hibridismo e outras misturas. São Paulo: Boitempo, 2004.

Cabo Verde: o contato de culturas. In: De vôos e ilhas: literatura e comunitarismos. São Paulo: Ateliê Editorial, 2003, p. 263-312.

ANDERSON, Benedict. Nação e consciência nacional. São Paulo: Ática, 1989.

ANDRADE, Mário de. Macunaíma: o herói sem nenhum caráter. São Paulo: Círculo do Livro, 1991.

ANDRADE, Oswald de. Manifesto antropófago. In: TELLES, Gilberto Mendonça (Org.). Vanguarda européia e modernismo brasileiro. Petrópolis: Vozes, 1985.

. Manifesto da Poesia Pau-Brasil. In: TELLES, Gilberto Mendonça. (Org.). Vanguarda européia e modernismo brasileiro. Petrópolis: Vozes, 1985.

BAKHTIN, Mikhail. Os gêneros do discurso. In: Estética da criação verbal. 6a ed., São Paulo: Editora WMF Martins Fontes, 2011, p. 261-306.

CABRAL, Amílcar. P.A.I.G.C. Unidade e luta. Lisboa: Publicações Nova Aurora, 1974.

CANDIDO, Antonio. O direito à Literatura. In: Vários escritos. $4^{\mathrm{a}} \mathrm{ed.}$., São Paulo/Rio de Janeiro: Duas Cidades; Ouro sobre o azul, 2009, p. 169191.

. Literatura e sociedade: estudos de teoria e história literária. $8^{\text {a }}$ ed. São Paulo: T. A. Queiroz, 2002.

COELHO NETO, José Teixeira. Arte e utopia: arte de nenhuma parte. São Paulo: Brasiliense, 1987.

FERREIRA, Manuel. A aventura crioula. Lisboa: Plátano Editora, 1985. 
- (Org.) Claridade: revista de arte e letras. $2^{\text {a }}$ ed., Linda-a-velha [Portugal]: A.L.A.C., 1986.

FRY, Peter; VOGT, Carlos. Cafundó: a África no Brasil. São Paulo/ Campinas, Companhia das Letras; Editora da Unicamp, 1996.

GOMES, Maria Alice Correia Forte Alcobia. Projecto multidimensional para a aprendizagem da Língua Portuguesa em Cabo Verde. Lisboa/ Praia, APILP, 1996.

HALL, Stuart. A identidade cultural na pós-modernidade. $4^{\text {a }}$ ed., Rio de Janeiro: LP\&A, 2000.

HERNANDEZ, Leila Leite. Os filhos da terra sol: a formação do Estado-nação em Cabo Verde. São Paulo: Summus, 2002.

HOUNTOUNDJI, Paulin. True and False Pluralism. African literature. Oxford: Blackwell Publishing, 2010.

LEITE, Ana Malfada. Oralidades e escritas pós-coloniais: estudos sobre literaturas africanas. Rio de Janeiro: Eduerj, 2012.

. Perspectivas teóricas e críticas nas literaturas africanas \& a perspectiva pós-colonial. Diadorim. Rio de Janeiro: UFRJ, número especial, p. 142-149, 2016.

LIMA, Norma Sueli Rosa. Claridade revista (2000-2013). In: GOMES, Simone Caputo; MANTOVAN, Antônio Aparecido; PEREIRA, Érica Antunes (Orgs). Literatura cabo-verdiana: leituras universitárias. Cáceres: Ed. Unemat, 2015, p. 124-135.

. Revisitando Claridade: o encantamento da poesia cabo-verdiana com o modernismo brasileiro. Niterói: UFF, 2000. (Tese de Doutorado)

MATA, Inocência. A crítica literária africana e a teoria pós-colonial: um modismo ou uma exigência? O Marrare. Rio de Janeiro: UERJ, $\mathrm{n}^{\circ} 8$, 2005, p. 21-30.

PETTER, Margarida (Org.) Introdução à linguística africana. São Paulo: Contexto, 2015.

SANTILLI, Maria Aparecida. Paralelas e tangentes: entre literaturas de língua portuguesa. São Paulo: Arte e Ciência, 2003.

VEIGA, Manuel. O crioulo de Cabo Verde: afirmação e visão prospectiva. In: HOLM, John; LANG, Jürgen; ROUGÉ, Jean-Louis; SOARES, Maria João (Orgs.). Cabo Verde: origens da sua sociedade e do seu crioulo. Alemanha, Fundação Fritz-Thyssen, 2006, p. 27-39. 
. Le creole du Cap-Vert: étude grammaticale descriptive et contrastive. Paris: Éditions Karthale; Praia: Instituto de Promoção Cultural, 2000 .

. Cabo Verde: insularidade e literatura. Paris: Éditions Karthale, 1998.

Recebido para publicação em 08/11/2016

Aprovado em 29/11/2016

\section{NOTAS}

1 Professora Adjunta do Departamento de Letras da UERJ-FFP; Coordenadora da Pós-Graduação em Educação Básica da Modalidade Ensino de Língua e das Literaturas de Língua Portuguesa.

2 Sigla para "crioulo cabo-verdiano". 